\title{
A FENOMENOLOGIA SEM ORIGEM: GÊNESE E ACONTECIMENTO*
}

\author{
André Dias de Andrade** \\ https://orcid.org/0000-0002-5962-7065 \\ andre8ada@gmail.com
}

RESUMO Reconstituímos o problema da gênese em sua dimensão mais fundamental na fenomenologia da temporalidade. Em seguida, mostramos em que condições ele pode ser recolocado a partir de uma fenomenologia do movimento e, finalmente, dispensado numa fenomenologia da diferença em vias de elaboração. Trata-se de um encaminhamento para o problema do logos fenomenológico: em que medida ele pode ser reformulado sem que, com isso, se perca a consistência da fenomenalidade.

Palavras-chave Husserl, Merleau-Ponty, fenomenologia, tempo, movimento.

ABSTRACT In this paper we rebuild the problem of genesis in its most fundamental dimension in phenomenology of time. Then, we show under what conditions can it be relocated from a phenomenology of movement to, finally, be dismissed by a phenomenology of difference in preparation. We propose a development of the problem of logos within phenomenology: to what extent can this problem be reformuled without losing the consistency of phenomenality?

Keywords Husserl, Merleau-Ponty, phenomenology, time, movement. 


\section{A origem}

O problema da gênese não é apenas o principal problema da fenomenologia em sua acepção mais tradicional, mas aquele por meio do qual ela obtém seu estatuto de filosofia, já que a possibilidade de que algo se mostre enquanto tal na fenomenalidade - "no original", numa acepção axiológica, ou "de modo originário", noutra de cunho ontológico - se confunde com a possibilidade da própria fenomenologia. Uma origem do fenômeno apreendida no fenômeno, que tem nele seu sentido de originariedade, para além da qual se dispensa perscrutar uma causa oculta, como capaz de conferir o estatuto científico da descrição fenomenológica. E, assim, este estudo por excelência descritivo depende da iminência de um logos apreendido no próprio modo como as coisas se manifestam, para que toda a distância do "fenomenismo" à "fenomenologia" seja garantida. O que se conquista através de uma descrição que atua como a "reativação" sem sobras da origem fenomênica do fenômeno. Bem antes da descrição "genética", ainda no ínterim da descrição dita "estática", não era afinal de contas a isto que aludia o "princípio dos princípios"?

Nenhuma teoria imaginável pode nos induzir em erro quanto ao princípio de todos os princípios: toda doação doadora originária é uma fonte de legitimação do conhecimento, tudo que nos é oferecido originariamente na "intuição" (por assim dizer, em sua efetividade em carne e osso) deve ser simplesmente tomado tal como ele se dá, mas também apenas nos limites dentro dos quais ele se dá. (Husserl, 2006, §24, p. 69)

Buscar o conhecimento na intuição e num intuição "originária"; enquanto se dá e nos limites em que se dá. Certamente que esta origem não possui um conteúdo específico - ela é sem "objeto" capaz de preencher sua visada - e remonta ao modo de olhar primordial a partir do qual, doravante, os conteúdos poderiam então ser considerados ou organizados em espécie. $\mathrm{O}$ "princípio dos princípios" não era apenas a restrição da episteme aos limites da intuitividade. Mas também reivindicava uma unidade para este intuicionismo, capaz de fundar ela mesma, numa espécie de origem intuitiva da própria intuição, com o "estudo da gênese". É assim que Husserl o caracteriza.

Vemos desde já em qual sentido pode ser questão um estudo da gênese. Não se trata de uma cronologia (de uma história em geral, ou de uma 'história' individual), nem de uma gênese do conhecimento em todos os sentidos do termo; nós buscamos a operação produtora que permite o surgimento do juízo e do conhecimento em sua forma originária, aquela do dado na ipseidade: repetida quanto se queira, ela tem sempre o mesmo resultado, que é o mesmo conhecimento. O conhecimento, assim como o juízo, ou seja, aquilo que consideramos dado como tal, é precisamente não um momento real da atividade de conhecimento que permaneceria sempre o mesmo na repetição dessa atividade, mas um momento "imanente", de tal natureza que nas repetições ele é dado em sua ipseidade como idêntico a elas. Numa palavra, não é 
um momento imanente real ou individual, mas um momento imanente irreal, supratemporal. (Husserl, 1970, §5, p. 26)

Um dos leitores mais atentos a essa questão é Derrida. Não à toa, procura levar a questão ao limite, como "questão da possibilidade da questão" (Derrida, 1967, p. 251), pois que algo possa aparecer enquanto tal, que haja doação das coisas em sua presença, de que haja, simplesmente, "presença" de algo no original, condiciona a força das análises fenomenológicas. Condição que pode fazer do "princípio dos princípios" - a garantia da e do intuicionismo qua filosofia - tanto o fundamento de uma ciência quanto a queda mais violenta numa metafísica da presença, de que a fenomenologia constituiria o ápice. A “origem" aparece então como possibilidade e como exigência simultâneas do discurso fenomenológico. E é por isso que numa leitura retrospectiva de Husserl, começando com O problema da gênese e com sua Introdução à origem da geometria, Derrida traça gradativamente esta obsessão, ${ }^{1}$ que se preparava desde a "primeira" das Investigações Lógicas. O conceito de gênese lhe parece implicar duas "significações contraditórias", a do nascimento e da realização, de modo que "a existência de toda gênese parece ter como sentido esta tensão entre uma transcendência e uma imanência. Ela se dá como indefinido ontológico ou temporal e começo absoluto, continuidade e descontinuidade, identidade e alteridade" (Derrida, 1990, p. 8). Se, por um lado, "não há gênese sem origem absoluta", por outro, "todo produto genético é produto para outra coisa que si, levado para um passado, chamado, orientado por um futuro" (Derrida, 1990, p. 7). Daí então ela encontrar na temporalidade constituinte da consciência e nas sínteses passivas do tempo a sua formulação cabal, cuja trama queremos entretecer.

Cabe salientar que é também a respeito dessa questão que Derrida falará em impossibilidade da fenomenologia, já que ela seria trabalhada por algo que não se mostra, um índice irredutível à repetição, traço não intuitivo irredutivel à significação, escritura irredutivel à voz, ou alteridade irredutível à presença (todos arautos da différance), cuja ideia de "origem" ou de algo como "primeiro", em vez de consistir na sua força motriz, repousa como seu maior pressuposto metafísico. Tudo reside na impossibilidade, a cada vez retomada, de uma presentação "em original" (algo o que é, verdadeiramente, um truísmo: a Gegenwärtigung e a Präsentation são já a experiência do originário):

1 Todos os textos de Husserl possuem a "figura de pretextos" para este problema da gênese, "esse espetáculo não é originariamente possivel para e por uma consciência filosófica que não somente funda seu valor científico, mas ainda é suscitado nela, nela se engendra, nela se compreende? É a filosofia inteira que seria interrogada aqui a respeito de seu próprio sentido e de sua própria dignidade" (Derrida, 1990, pp. 1; 3). 
Afirmando que a percepção não existe ou que isto que se chama percepção não é originário, e que de uma certa maneira tudo "começa" pela "re-presentação" (proposição que evidentemente apenas pode se sustentar na rasura desses dois últimos conceitos: ela significa que não há "começo" e a "re-presentação" de que falamos não é a modificação de um "re-" sobreposta a uma presentação originária), reintroduzindo a diferença do "signo" no coração do "originário", não se trata de retornar para aquém da fenomenologia transcendental, quer a um "empirismo" ou a uma outra crítica "kantiana", da pretensão à intuição originária (Derrida, 1967, p. 50; nota). ${ }^{2}$

A ideia de gênese ou de presença em original é derivada e depende de uma facticidade irredutível, mas, sobretudo, não fenomênica, tal como a ideia de "primeiro" é sempre derivada e, portanto, "segunda", o que evidencia sua predileção por uma "metafísica segunda" que quebre tal metafísica supostamente "primeira" (a Metafísica da Presença) e que é desenvolvida até sua Arqueologia do Frívolo (Derrida, 1973, p. 9 ss). Ora, mas se não há originário, ou se o originário é "segundo" e derivado, é a própria consistência inerente à fenomenalidade que está comprometida e, com isso, todo o edifício fenomenológico. Não há percepção, não há coisa ela mesma, não há logos. $\mathrm{O}$ que leva ao abandono da fenomenologia junto da derrocada da origem, pois é ela que fornece a amarração das análises fenomenológicas, a certeza prévia de que existe nexo entre as aparências - justamente, o nexo fenomeno-lógico. E a maior realização da fenomenologia está na constatação de seu fracasso, de sua impossibilidade, o que, na letra, é muito próximo daquilo que outro leitor de Husserl, num tom menos dissidente, escrevia anos antes. A saber, que o maior ensinamento da redução é a impossibilidade de uma redução completa (Merleau-Ponty, 1945, p. viii) e, em um de seus últimos escritos, que a redução fenomenológica tinha o mérito de nos colocar em contato com o irredutível, com a "tese do mundo" que precedia a todas as teses teóricas e, por isso, persistia à redução (Merleau-Ponty, 1968, p. 207). Curioso notar como Merleau-Ponty chegava a essa concepção em uma perspectiva que poderíamos denominar intrafenomenológica, cujo desdobramento lhe parecia ser o prosseguimento mais conforme ao espírito desta filosofia, daquilo que ela

2 O debate na John Hopkins University um ano antes (1966) já trazia o mesmo diagnóstico, que ali se expandia para a fenomenologia de extração francesa, quando Serge Doubrovsky pergunta sobre a "intencionalidade corporal" tal como formulada por Merleau-Ponty. Derrida responde: "... eu simplesmente estou pensando aqueles conceitos que fundam o movimento da intencionalidade. Quanto à percepção, devo dizer que já reconheci ela como uma conservação necessária. Eu fui extremamente conservador. Agora, não sei o que é percepção e não creio que algo como a percepção exista. A percepção é precisamente um conceito, um conceito de uma intuição ou de um dado que se origina da coisa ela mesma., presente ela mesma em seu significado, independente da linguagem, e do sistema de referência. E creio que a percepção é interdependente com relação ao conceito de origem e de centro e, consequentemente, tudo o que recai sobre a metafísica da qual falei recai também no conceito de percepção. Não creio que exista alguma percepção" (Derrida apud Macksey; Donato, 1970, p. 272). 
mesma demandava e propunha como a "sombra" não escrita e impensada de seu fundador. Nessa feita, parece que as descrições não levavam completamente para fora da experiência, do dado e da percepção, mas para um limite interno à sua própria noção de sentido, o que impelia a reformular a fenomenalidade, em vez de sublevá-la. É essa hipótese heurística que desenvolvemos aqui com o intuito de avançar o debate sobre o estatuto da fenomenologia.

\section{Temporalidade e presença}

Primeiro, cabe analisar os termos com que Merleau-Ponty define o problema. Para este a filosofia é sempre a tematização do contato com aquilo que, não obstante, nos excede. Como pode uma subjetividade abrir-se a um mundo de que ela não somente partilha das diversas formações de sentido, mas um mundo que também possui uma transcendência própria e pode ser mais, diferente e alheio a ele mesmo? Como pode o corpo, que é sujeito encarnado e possui agência neste logos do mundo, ser incapaz de esgotar este logos em sua integralidade? Como pode ele estar em relação direta e sem intermédios com algo que lhe ultrapassa e comporta um sentido positivo de indeterminação, um índice de "para além” irremediável? Destarte as mudanças conceituais no tratamento dessa questão, é o modo desta transcendência sensível que ele interroga durante toda a sua obra. Em 1945 é assim que ele a apresenta:

Vê-se então nosso problema. É preciso que o sujeito perceptivo, sem abandonar seu lugar e seu ponto de vista, na opacidade do sentir, dirija-se para coisas das quais antecipadamente ele não tem a chave, e das quais, todavia ele traz em si mesmo o projeto, abra-se a um Outro absoluto que ele prepara no mais profundo de si mesmo (Merleau-Ponty, 1945, p. 376).

E a resposta, neste primeiro momento, advém da temporalidade. É o tempo responsável pelo logos, sendo que todas as modalidades da transcendência - o mundo em suas dimensões natural e social, na percepção, na linguagem e na intersubjetividade - também devem ser apreendidas a partir da temporalidade, já que "a solução de todos os problemas de transcendência se encontra na espessura do presente pré-objetivo" (1945, p. 495) e que "tempo e sentido são um e o mesmo" (Merleau-Ponty, 1945, p. 487). Como misto de passagem e permanência, fluxo e intuitividade, o tempo figura como princípio organizador da fenomenalidade e é o responsável pela medida da vida perceptiva e das coisas que nela figuram, de modo que "seria mais exato dizer que nada existe e que tudo se temporaliza" (1945, p. 383). Segundo esse modelo, o tempo é responsável pela gênese do sentido e funciona como articulador de todas as coisas, da identidade e da diferença entre sujeito e mundo, da semelhança e 
da oposição entre as aparências e, finalmente, do mesmo e do outro. Perante a temporalidade o paradoxo da imanência e da transcendência constitutivo da fenomenologia encontra um primeiro ensejo de resolução. ${ }^{3}$ Paradoxo que passa a ser a condição e o limite do discurso filosófico. É por isso que a passagem do tempo pode ser considerada como genética e sua gênese é aquilo que devemos chamar de presença - "a explosão ou a deiscência do presente em direção a um porvir é o arquétipo da relação de si a si e desenha uma interioridade ou uma ipseidade" (Merleau-Ponty, 1945, p. 487) - e o tempo é uma espécie de espectador que dá a si mesmo como espetáculo e, nessa feita, está na gênese da fenomenalidade. $\mathrm{O}$ tempo fenomenológico nada tem a ver com o tempo objetivo, aquele do relógio e que cremos transcorrer independente da nossa experiência - é um tempo subjetivo, ou a própria subjetividade tal qual temporalização, reformulada por Merleau-Ponty como temporalidade da percepção. Nisso, ele possui ainda uma estrutura, aqui denominada "estrutura única que é a presença" (Merleau-Ponty, 1945, p. 492) ou "campo de presença" (cf. sobretudo 1945, pp. 307; 475, 484) com suas características e sínteses próprias, que remontam às descrições de Husserl. Assim, a solução estaria indicada já nos estudos husserlianos: "tal é o paradoxo disso que se poderia denominar, com Husserl, a 'síntese passiva' do tempo - uma expressão que evidentemente não é uma solução, mas um índice para designar um problema" (MERLEAU-PONTY, 1945, p. 479), o que aparece nas Lições de 1905 com o nome de genesis spontanea, quando em seu primeiro apêndice Husserl disserta a respeito do porquê de haver uma consciência impressional e, por meio dela, a experiência do tempo a partir do "agora". É preciso que essa impressão "não seja produzida" e não apareça como algo derivado, mas, justamente, como

3 Além disso, cabe salientar que desde a A estrutura do comportamento é esta medida temporal que confere inteligibilidade à intencionalidade perceptiva e que distingue, sem separá-los completamente, os diversos tipos de organização atinentes ao mundo físico, orgânico e humano - "as dimensões fundamentais do tempo e do espaço se reencontram, se quisermos, nos três níveis que acabamos de distinguir,. Mas elas não têm ali o mesmo sentido" (Merleau-Ponty, 1942, p. 114). A temporalidade permite compreender a percepção propriamente humana como intencional no sentido forte, intencionalidade "noemática", já que junto da "multiplicidade perspectiva" ela visa a um "mesmo tema" (1942, p. 133) como um polo que permanece o "mesmo" em suas variações (e falta aos símios nas experiências de Köhler esta capacidade para ver a "mesma" caixa como caixa-suporte e caixa-instrumento; 1942, p. 127 ss). Na Fenomenologia da Percepção, é a intencionalidade operante do tempo que fenomenaliza a organização gestáltica do sensível, a relação indissolúvel entre organismo e meio, bem como as formações intersubjetivas do mundo cultural e da linguagem, visto que neste momento a gestalthaft não pode ainda funcionar por conta própria. Mas ela só o faz porque esta compreensão da ordem humana como intencionalidade noemática (que pressupõe uma visada referencial à caixa "ela mesma", da qual a caixa-suporte e a caixa-instrumento atuam como "perfis") já estava preparada. Mesmo leituras mais recentes não notam esta filiação a um modo de ver clássico. Quanto a isso cabe ressaltar o extenso e contundente livro de Fabrice Colonna, Merleau-Ponty et le renouvellement de la métaphysique que denuncia um "mal entendido" com as leituras fenomenológicas de Merleau-Ponty (Colonna, 2014, p. 68 ss) onde, a nosso ver, existiria na verdade um pressuposto fenomenológico (e filosófico, mais geral) que cabe analisar e à medida do possível extirpar. Reencontraremos esta questão à frente. 
impressão primeira e originária, Urimpression, pois "como genesis spontanea, ela é protoprodução [Urzeugung]” (Husserl, 1984, p. 124; HUA X, p. 100). É preciso rastrear essa questão e nos aproximarmos ainda mais da "origem", que agora sabemos estar na gênese temporal do sentido.

Sabemos que o modelo para a unidade entre saber e subjetividade capaz de erigir a fenomenologia em filosofia está nas investigações husserlianas a respeito da temporalidade. Não à toa as Lições para uma fenomenologia da consciência interna do tempo foram organizadas com esse título: porque a significação mais própria da consciência está na temporalidade, e porque ela é o tempo. ${ }^{4} \mathrm{E}$, quando procuramos saber do porquê de a consciência do tempo ser consciência "do" tempo, e não apenas consciência (que tem uma duração) temporal, tal como as coisas que possuem sempre uma duração determinada, Husserl adverte que a resposta é "chocante" (Husserl, 1984, § 39), já que ela precisa ter sua unidade fundada nela mesma. Ora, o que surpreende é que a passagem do tempo deve, de algum modo, saber de si mesma enquanto passa, isto é, sem deixar de passar e, nisso, cair da qualidade de tempo constituinte para a de tempo constituído ou mero estado de consciência que dura. A relação entre o tempo que passa e o tempo que intui esta passagem - constituído e constituinte - deve ser absoluta, a temporalidade possui uma forma e essa forma deve ser ela também temporal, sem o que deixaria de constar na descrição e, portanto, levaria a filosofia para fora da fenomenologia. Assim, a fenomenologia genética não deveria ser metafísica, mas a descrição da origem do sentido das coisas no próprio acontecimento de sua aparição. À questão a respeito de "como é possível saber da unidade do fluxo constituinte último da consciência" (Husserl, 1984, §39, p. 106; Hua X, p. 80) Husserl então responde:

o fluxo da consciência auto constituinte do tempo não é apenas, mas ele é de uma maneira tão notável, e, no entanto, compreensível, que nele se dá necessariamente uma auto aparição do fluxo, a partir da qual o próprio fluxo deve poder ser necessariamente captado no [seu] fluir. A auto aparição do fluxo não exige um segundo fluxo, mas ele, como fenômeno, constitui-se antes a si e em si mesmo (Husserl, 1984, §39, p. 107-8; Hua X, p. 83).

Então o tempo não é apenas predicado fundamental de tudo o que aparece, ele não é apenas o Quid do sentido, mas é responsável pela gênese

4 Como bem notou Moutinho, que recupera a tradução francesa de inneren como intime, "que significa, em Husserl, não uma consciência interna do tempo, mas uma consciência que seja ela próprio tempo, fluxo absoluto; a 'intimidade' a que se refere Husserl [...] começa por exigir uma Ausschaltung do tempo objetivo para interrogar apenas o tempo imanente do curso da consciência: o Datum fenomenológico é o tempo imanente" (Moutinho, 2004, pp. 26-27). 
da fenomenalidade, o Quod do sentido. Mesmo o espaço, o "ser-posto-um-dolado-de-outro" possui seu sentido a partir do seu "estar-junto num único tempo" (Husserl, 1970, §36, p. 188) e ser "após" ou "antes" do outro, como reafirma em Experiência e Juízo. Nesses textos tardios lemos que o tempo é "a forma primeira, a forma fundamental, a forma de todas as formas, o pressuposto de todas as outras conexões instauradoras de unidade" (Husserl, 1970, §38, p. 196), que instaura o sentido da percepção e da consciência primária dos dados sensíveis, bem como de sua ligação, como uma consciência presentativa, ou intuitiva a partir do presente, "na unidade de uma presença intuitiva" (Husserl, 1970, §42, p. 218). Cabe notar que o dado mínimo de sentido é uma "presença", sob esta forma transitiva da temporalidade, como presentação (Gegenwärtigung) que possui seus desdobramentos posicionais na re-presentação, rememoração, imaginação (todas modalidades da Ver-gegenwärtigung) e, mesmo, despresentação (como Ent-gegenwärtigung). ${ }^{5}$

Nada surpreende mais Husserl do que o fato de que toda experiência aparece já unificada, que algo como um mundo ou um objeto aparecem, e não um caos de sensações ou dados aleatórios. De modo que toda experiência é já resultado de uma síntese, mesmo que de uma síntese passiva, justamente a "gênese" já operada e que pode ser reativada. ${ }^{6}$ A garantia da fenomenologia contra o fenomenismo está nesse logos e no encadeamento entre as aparições. Elas se mantêm, confirmam ou anulam, mas possuem todas uma unidade já dada; e o rio de Heráclito é, justamente, um "rio", porque ele possui uma forma no seu escoar incessante. Presente, passado e futuro são partes ou momentos de uma totalidade concreta denominada Präsenzfeld, de um "ímpeto único" recuperado por Merleau-Ponty numa metáfora ainda melhor: o tempo como um "jato de água" que mantém sua forma não apesar da variação, mas na variação e enquanto variação (Merleau-Ponty, 1945, p. 482).

Outro modo de conceber o tempo como este princípio genético para a fenomenalidade está na diferença entre duas percepções ou entre uma única e seu desaparecimento, como se a experiência da "diferença" entre um dado e ele mesmo fosse aquilo que de mais imediato podemos apreender. Este dado chama-se "presença", como sabemos, e ela é uma noção omniabarcante, pois mesmo sua contraparte na "não-presença", é parte integrante de sua natureza transitiva e uma modalidade de sua presentação. Não nos enganemos aqui com relação ao presente vivo, e é possível voltar ao texto de Husserl para mostrar como cada um dos conflitos que parecem colocar um ponto cego ou uma diferença no seio da temporalidade constituída - como aqueles da homogeneidade e da heterogeneidade, do parentesco e da estranheza (HUSSERL, 1970, §16, p. 87), bem como entre presente e não-presente $(1970, \S 15$, p. 88) - adquirem seu caráter conflitante a partir da própria noção de presente vivo e de tempo constituinte, em que "a identidade da determinação temporal constitui a prévia deste conflito” (Husserl, 1970, §38, p. 195; cf. §42, p. 211). 


\section{0 pressuposto da origem}

E aqui chegamos a uma questão crucial. Pelo fato de a consciência primária na fenomenologia ser a consciência do tempo que a modalidade originária de doação deve se dar no presente ou como presentação (Gegenwärtigung) e não representação (Ver-gegenwärtigung). Nesse modelo a coisa passa a ter um sentido preciso: ela é apreendida como algo transcendente, que possui uma indeterminação constitutiva e que jamais pode - nem deveria - ser abarcada adequadamente, senão por meio dos seus "perfis" e, ao mesmo tempo, ela é apreendida como algo imanente, que não lhe é completamente estranho, e, outrossim, deve poder esgotar-se de algum modo nesta apreensão, como presença de uma norma que se lança ao infinito mas que, em cada um dos seus perfis ou "momentos", permanece a "mesma". É isso que amarra as descrições sobre o tempo das Lições (1905) à fenomenologia desenvolvida em Ideias I (1913) e a fenomenologia genética da década de 1920, pois se no primeiro caso o fluxo do tempo é apreendido a partir da impressão originária do presente, em que a passagem e a permanência fazem um só fenômeno, no outro a multiplicidade perspectiva da coisa é apreendida junto da referência à sua "mesmidade", na camada central ou nuclear do noema, a partir da qual a transcendência e a imanência também fazem um só fenômeno. Em Ideias I Husserl faz menção a investigações colaterais sobre o tempo e explica que a temporalidade genética deve estar relacionada com uma temporalidade noemática, sendo papel de uma esclarecer reciprocamente a outra (Husserl, $2006, \S 83$, p. 188). Em cada caso, rigorosamente, é uma série diversa que se compreende ainda como "série" e que aponta para uma meta, e podemos afirmar que a incompletude do perfil faz par com a referencialidade dele a uma "mesma" coisa, seja no ponto-limite do presente, seja no núcleo noemático, através do qual o seu encadeamento é apreendido como "uma ideia no sentido kantiano" (Husserl, 2006, §83, p. 188; cf. §143), responsável por conciliar aquilo que está na atualidade do olhar e seus horizontes inatuais, de modo que na percepção sua "indeterminidade significa necessariamente determinabilidade segundo um estilo firmemente prescrito" (Husserl, 2006, §44, p. 103). Nesse tipo de intuição, a determinação completa do noema é inatingível, sempre carecendo de complementos que levam o reenvio intencional à verificação ou à decepção, mas sem jamais romper a unidade do fluxo.

Ora, poder-se-ia afirmar que quando Husserl investiga os estratos passivos da consciência - com o hábito, a afetividade, a percepção - ele quebra este paradigma da determinação completa. Como sabemos estaé a posição de MerleauPonty, para o qual "a intencionalidade operante (fungierende Intentionalität)" é justamente "aquela que faz a unidade natural e antepredicativa do mundo e 
de nossa vida" (Merleau-Ponty, 1945, p. xiii) sem que uma consciência precise ligá-las na atualidade e de modo explícito. Haveria então um elo mais antigo com o mundo e com a coisa, que não esgota sua transcendência. Mas a exigência da determinação imanente da transcendência será retomada a cada vez que Husserl investigar os estratos inferiores da intencionalidade e encontrar ali a forma vazia da determinabilidade, ou seja, quando passa do juízo que ativamente coloca a referência à percepção que passivamente também a intenciona - já no âmbito da fenomenologia genética. Quando na percepção eu "antecipo" os lados não vistos da coisa, evidentemente tal antecipação guarda uma "particularidade essencial de ser geral e indeterminada" (Husserl, 1970, §8, p. 41). Nada garante, de fato, que o lado antecipado corresponde àquilo que viso ou sequer à mesma coisa. No entanto "este arbitrário não é ilimitado" e ainda que a quididade da coisa possa variar e jamais ser completamente antecipada, a própria antecipação já é uma atividade que faz parte de seu a priori geral de coisa, de seu "préconhecimento": "é uma generalidade indeterminada, mas que permanece identificável como a mesma; é a generalidade de um tipo a priori pertencente a um espaço de jogo de possibilidades a priori" (Husserl, 1970, §8, pp. 41-2). É nesta referência da coisa como sendo a "mesma" que está a possibilidade de falar de sua indeterminação, pois sempre que viso uma coisa eu a viso junto desta tendência à determinação completa. E é nessa referência da coisa como sendo a "mesma" que está a impossibilidade de estabelecer sua indeterminação como positiva, vale dizer, como uma indeterminação que, enquanto visada, poderia abrir lugar à "outra coisa". "Generalidade indeterminada" e "particularidade determinada", é preciso sempre lembrar (1970, §8, p. 43); não há olhar do indeterminado, não há como observar $o$ indeterminado, porque o modo do olhar já o apreende como algo a ser determinado, determinável por direito, e, pelo menos nestas análises rigorosamente construídas, uma indeterminação em sentido positivo só poderia estar alojada fora do escopo da fenomenologia.

O que faz da coisa, justamente, uma "coisa" é o fato de ela ser antecipada pelo olhar como a "mesma"; a sua determinação lançada ao infinito como ideia no sentido kantiano. E o que define a fenomenologia é justamente a fixação do mecanismo referencial na origem da intencionalidade (ou, se quisermos, o que faz da intencionalidade o encontro com a origem: a intuição do originário ou a reativação do original), dupla exigência de seu logos, a partir da qual "um limite é posto à variação dos núcleos, limite que faz precisamente da lógica uma lógica do mundo, do ente mundano", e que permite entrever o pressuposto mais fundamental da ideia de intencionalidade, que "nunca fora formulada na lógica, nem apresentada como sua pressuposição fundamental" (1970, §9, p. 46). Assim, a referencialidade é parte integrante daquilo que se 
chama fenomenologia genética e que visa à descrição da camada originária da experiência e da experiência da coisa em seu original. "Com todo objeto novo constituído pela primeira vez (para falar a linguagem da análise genética), um novo tipo de objetos se encontra prescrito de maneira durável, em função do qual são apreendidos antecipadamente outros objetos semelhantes a ele" (1970, §8, p. 44).

A questão é que essa referencialidade que já preestabelece a adequação presuntiva de todo dado inadequado e, através disso, do fato à essência, coloca a fenomenologia de partida como uma eidética transcendental. E isso não é somente uma astúcia das intencionalidades propriamente téticas (e da dita "noética"), quando deliberadamente "pensamos" a respeito do múltiplo de modo a tentar apreendê-lo conceitualmente e ali isolar uma identidade (por exemplo, na variação imaginativa), mas é um caráter da intencionalidade em geral (e da própria noção de "coisa", de noema e, finalmente, de "coisa mesma"), que possui um centro referencial ao qual apontam seus perfis. Numa expressão: a pressuposição de que a fenomenalidade seja algo desde já referencial, sendo que, pelo menos nesse ponto, seria preciso concordar com Derrida que mesmo sem a garantia de uma causa ou propriedade comum aos fenômenos (uma arché), a variação fenomênica ainda é lançada ao infinito e reaparece como telos - e estaria aí o suposto metafísico da fenomenologia.

Mas fazendo isso, talvez estejamos pinçando um outro suposto, merleau-pontiano, quando conduz a fenomenologia para além dos quadros epistemológicos, em torno de questões existenciais como o corpo, o mundo sensível e a alteridade. Pois ali se conserva a concepção básica da intencionalidade como movimento em direção da coisa mesma ou, melhor, da "mesma" coisa; o que faz da consciência uma "presunção" mesmo que inatingível do universal e, finalmente, da fenomenologia uma pergunta renitente pela origem ou pelo originário. A questão da gênese é então preparada desde o momento em que se concebeu que a pura manifestação de algo visa também à sua completude ou, simplesmente, designa algo como "perfil" de "x". E, nessa feita, a fenomenologia da percepção tal como compreendida por MerleauPonty - leia-se: a descrição de um logos perceptivo ou do logos do mundo estético - ao conservar a intencionalidade noemática e o presente temporal como lugar da doação se recoloca na esteira da fenomenologia transcendental, já que o modelo de compreensão da fenomenalidade e de seu logos é o mesmo, embora as descrições possam ser reelaboradas. ${ }^{7}$ Há na exigência de um núcleo 
noemático, na doação a partir do presente temporal e, finalmente, numa relação a si de toda percepção (a consciência pré-reflexiva denominada nessa época de cogito tácito, e que não examinamos detalhadamente neste trabalho) três figuras do "centro" a partir das quais Merleau-Ponty concebe o logos fenomenológico e a intencionalidade de acordo com essa presunção referencial. Todas elas remontam à noção de sentido como presença, a qual consiste em um intervalo entre o dado (no perfil) e ele mesmo (na sua Selbstheit) e que obriga a pensá-lo de modo referencial. Não à toa, Merleau-Ponty remete todas as suas descrições ao "campo de presença", seja na percepção, com o encadeamento noemático (Merleau-Ponty, 1945, pp. 109; 307), na subjetividade, com o cogito préreflexivo (p. 382) ou no logos perceptivo, com a doação a partir do presente temporal (pp. 475-476). Para citar apenas sua passagem conclusiva: "O fluxo absoluto se perfila sob seu próprio olhar como 'uma consciência' ou como homem ou como sujeito encarnado, porque ele é um campo de presença presença a si, ao outro e ao mundo - e porque essa presença o lança no mundo natural e cultural a partir do qual ele se compreende" (p. 515). Curiosamente é na sequência dos escritos de Merleau-Ponty que vislumbramos um deslocamento de todo esse problema e do ferramental conceitual para lidar com ele.

\section{Movimento e diferença}

A temporalidade como fator genético da percepção desaparece no início dos anos 1950 e cede lugar ao movimento, num sentido fundamental, como "mobilidade a priori" ou como "revelador do ser" (Merleau-Ponty, 2011, pp. 99-100). Nessas novas investigações que começam por uma "redefinição da noção de consciência e de sentido" (Merleau-Ponty, 1953/2011, p. 35) notamos que, ao contrário do tempo cuja unidade mínima de sentido era uma "presença" ou "intuição" - nos moldes da consciência primária da Gegenwärtigung -, com o movimento esta unidade será um "desvio", "intervalo" ou "diferença", todos termos que expressam o écart, cuja doação passa a ser considerada a partir

Percepção tenham que ser reconduzidas a uma compreensão conceitual que compromete a encarnação da subjetividade no corpo e o enraizamento do sentido no mundo, na última parte da obra. Seja o diagnóstico de intelectualismo (Barbaras, 1991, p. 34), idealismo (Ferraz, 2009, pp. 42 ss), subjetivismo (Peillon, 1994, pp. 165-166) ou até mesmo platonismo (Moura, 2001, p. 313), toda esta importante gama de leituras funciona também como uma ode aos desserviços que o cogito tácito presta à lógica perceptiva que se supunha apreendida pelo corpo próprio. Controvérsias à parte, esta primeira "fase" dos escritos merleau-pontianos não nos parece comprometida apenas pela aparição do cogito pré-reflexivo, como propomos na sequência deste artigo, e sim pela pressuposição de que o logos da percepção possua uma dinâmica referencial. Em outro artigo seu, Moura é preciso a respeito desse problema quando conclui que “o código 'fenomenológico', desde que bem compreendido, sempre nos transporta a uma instância situada fora do mundo, quer dizer, fora do tempo, pouco importando que este sujeito atenda pelo nome de 'Si' ou de 'ego originário'” (Moura, 2008, p. 31). 
das análises estruturais e sistêmicas da língua, já num passo interpretativo que as conduz a uma nova teoria da percepção. Enquanto a linguística estrutural atribui o sentido do signo e da fala a partir de uma diferença entre ele e os outros signos no ínterim do sistema, numa atribuição "diacrítica" de seu valor, o sentido do percebido se torna uma diferença entre as qualidades sensíveis, as hyleen, já que elas passam também a se estruturar de modo diacrítico. Num sentido renovado é a lógica autóctone do mundo que é mais uma vez aqui considerada, em suas dimensões sensível e expressiva (tal como apontam as preleções de 1953 sobre $O$ mundo sensível e o mundo da expressão). Contudo, mais do que uma repetição das teses já defendidas pelo autor a i) modalidade diacrítica de doação do sentido (com o écart) e sua ii) organização a partir do movimento e da mobilidade (ao invés vez do tempo) lançam novas bases para pensar a fenomenologia. Pois a linguística estrutural permite a MerleauPonty abordar a gestalt e a fenomenalidade como uma estrutura que procede por diferenciação interna e que prescinde de um elemento central que venha intencionalizá-la e recolher o seu sentido, o que no primeiro modelo lançava o seu acabamento num horizonte presuntivo de adequação. Sabemos que isso é novo, pois desde a sua primeira obra é a ideia de intencionalidade que preenchia as formas percebidas com uma significação positiva, impedindo-a de cair no fisicalismo ou no intelectualismo ainda renitentes de Köhler, Koffka e Goldstein. A forma não podia ser "coisa", nem "ideia"; ela precisava então ser "percebida" (Merleau-Ponty, 1942, pp. 101-2; 138; 227), o que só era possível se a percepção consistisse num modo original de relação com o ser. Isso só era conquistado ao preço de resguardar um centro referencial e préreflexivo a partir do qual ela adquiria sentido, pois, nessa época, permanecia compreendida a partir da temporalidade e da consciência originária do presente. Em todos os textos de Sens et non-sens que tratam da gestalt perceptiva e da estrutura linguística, mesmo mencionando Saussure, é sempre a primeira que deve esclarecer a segunda - "talvez a noção de Gestalt ou de estrutura prestaria aqui [na linguística] os mesmos serviços que na psicologia" (Merleau-Ponty, 1966, p. 153) -, e é por isso que a dinâmica diacrítica da estrutura ainda não é considerada em si mesma.

Como a psicologia da forma reivindica o uso de conceitos descritivos emprestados de nossa experiência humana, e que não poderiam substituir conceitos fundamentais, fundados à medida das variações correlativas, a linguística de Saussure legitima, no estudo da língua, além da perspectiva da explicitação causal que vincula cada fato a um fato anterior e então desdobra a língua diante do linguista como um objeto de natureza, a perspectiva do sujeito falante que vive sua língua (e eventualmente a modifica) (Merleau-Ponty, 1966, p. 152; itálicos meus). 
Interessa, sobretudo, a propriedade de "totalidade" não adjacente, irredutível à soma de partes, já conquistada pela Gestalttheorie e que seria confirmada pela linguística no que tange à gestalt verbal. Ora, quando a organização por diferenciação passa a ser reconsiderada, na década de 1950, será então a estrutura linguística - principalmente no seu modo de estruturação - que esclarecerá a gestalt perceptiva e, com isso, recolocará o problema da percepção. Em suma, se a relação entre corpo e mundo passa a ser pensada tendo como base uma diferenciação que funciona de modo análogo àquela do sistema linguístico e fonemático, ${ }^{8}$ de modo que a posição, conduta, percepção ou fala é a cada momento um desvio com relação ao sistema do mundo, MerleauPonty pode responder à questão "por relação a quê se faz o desvio de um ou de outro?" deste modo: “o paradoxo aqui é o mesmo que nos signos: os signos são diacríticos, isto é, cada um marca uma diferença de significação e não uma significação" (Merleau-Ponty, 2011, p. 178), e "daí resulta [uma] transformação completa disso que se pode entender por: perceber o espaço ou perceber as coisas" (Merleau-Ponty, 2011, p. 179). ${ }^{9}$ Mas, é preciso questionar por que e como ocorre esta diferenciação que passa a ser o modo básico de compreensão da fenomenalização. A resposta virá pela consideração do movimento, que passa a ser princípio de fenomenalização na nova abordagem que MerleauPonty faz da psicologia.

Através dos experimentos de Ternus, Duncker, Brown, Michotte dentre outros Merleau-Ponty descobre uma mobilidade primordial do campo, a partir da qual ele se estrutura em figuras, fundos, desvios, níveis e normas, tanto espaciais e temporais, quanto sensíveis e expressivos. Para permanecer apenas numa dessas leituras, a de La perception de la causalité de Albert Michotte e que é crucial até os escritos finais de Merleau-Ponty, a descrição dos fenômenos de agenciamento e de autolocomoção constatam sua dependência com relação aos fatores de campo, de modo que os elementos do campo agora contribuem também para a percepção de uma "causa" e de um "efeito", de

8 Justamente aquilo que ele demanda do estruturalismo ainda na década de 1940, em seus cursos da Sorbonne, quando interpela Jakobson: "Então, o sistema fonemático parece ser uma realidade irredutível e a aquisição da linguagem parece ser uma integração do indivíduo em sua estrutura da linguagem. Isso fica bastante claro na transição do balbucio à articulação das palavras" (Merleau-Ponty, 1988, p. 15). Contudo, resta ainda fazer a filosofia desta diferenciação primordial do campo linguístico e, daí, perceptivo, dando-lhe a justa compreensão, pois "Jakobson está menos preocupado com o estatuto ontológico do sistema fonemático do que em enumerar suas propriedades” (Merleau-Ponty, 1988, p. 16).

9 E é nestes anos que se constrói a resposta à nota anterior: "Assim como o sujeito falante só compreende e fala como possuidor de sistema de gesticulação definido por dimensões de variação, o sujeito que percebe o movimento só pode fazê-lo enquanto possui as equivalências de um tipo de língua natural: os campos sensoriais são isto, sistemas diacríticos dados com valores de emprego, equivalências características. Mas entre esses campos há também equivalências e como que uma língua comum desses dialetos" (MerleauPonty, 2011, p. 111). 
um "agente" e de um "paciente". A impressão de causalidade depende única e exclusivamente do conjunto sensível e, então, resolve-se no campo perceptivo. O que levanta a possibilidade de que o movimento atue como fator primordial para a fenomenalidade, a partir do qual os elementos do campo passam a ter um "sentido", uma "interioridade", uma relação a "Si" (exatamente o que era tornado possível pelo recurso à temporalidade) e, consequentemente, exprimem um logos próprio. Isso leva a um círculo descritivo no qual o sentido do movimento é apreendido com o movimento efetivo e não a partir de uma síntese intelectual ou de um espaço homogêneo que lhe serviriam de condição de possibilidade. Essa é a diferença entre descrever isto pelo quê há sentido (ce par quoi), típico do procedimento fenomenológico merleau-pontiano, e não apelar para aquilo sem o quê (ce sans quoi) não haveria sentido, um porquê descolado e anterior ao próprio sentido - sendo que não há "prioridade cronológica ou transcendental (= segundo relações nocionais) de espaço por relação a movimento" (MerleauPonty, 2011, p. 70). Assim, o movimento e o sentido passam a ser um único fenômeno, no qual a gestalt e a gestalthaft se dão conjuntamente e, neste caso, sem a síntese originária e passiva do tempo: "o movimento é compreendido na estrutura da figura; mas reciprocamente a estrutura da figura só é permanente por meio do movimento, no movimento" (Merleau-Ponty, 2011, p. 98). Ver a figura é, na mesma feita, desdobrar seu movimento ou assistir à sua enformação. Acompanhar o movimento é, reciprocamente, acompanhar a segregação de um campo movente, de um desvio móbil e de um fundo ou nível estacionário. Mas é preciso tomar cuidado com esta passagem entre uma i) mobilidade da estrutura (na segregação do campo em écart e niveau, coisa que o "fenômeno phi" já demonstrava) para uma ii) autolocomoção da estrutura (na diferenciação interna ao campo, responsável pelo sentido e que se situa no nascimento da percepção), pois agora não é apenas o sentido que se enraíza no campo perceptivo, pela via do movimento, mas também o próprio logos que passa a ter uma produtividade e transcendência sob nova chave. ${ }^{10}$ Por isso cabe nos aprofundarmos nessa descoberta de um tipo novo de transcendência no movimento.

10 Se na Estrutura do Comportamento já havia uma tentativa de enraizar a atitude categorial no corpo, já que Schneider possui uma conduta intencional análoga aquela dos chimpanzés de Köhler que só conseguiam se referir a um sentido de cada vez, todo este quadro deverá agora ser revisto. Bem entendido, não se trata mais de enraizar a atitude categorial no mundo percebido, o que fazia a fortuna da passagem entre a descrição gestáltica do comportamento para a análise intencional com a Fenomenologia da Percepção. Este primeiro projeto salvaguardava a racionalidade em sua base, o que permitia a comensurabilidade entre as diferentes condutas perceptivas, do "malogro" dos animais e dos doentes ao "sucesso" da conduta normal e categórica, bem como vinculava as diferentes experiências do mundo (desde o espaço mítico até o espaço objetivo; cf 1945, pp. 338-9) sem que se fizesse da razão uma constituição transcendental do mundo e das experiências. Pelo contrário, agora o projeto é retirar a primazia desta referencialidade e da teleologia incipiente da própria concepção de percepção ou de intencionalidade como um todo: "Para passar à ideia de espaço, é preciso 
Michotte verifica por meio de uma série de experimentos que a percepção do agenciamento causal (por "lançamento" ou "acionamento"), bem como aquela do agenciamento interno (por "entranhamento"), podem ser induzidas apenas a partir de fatores de campo (um conjunto de caixas manejadas mecanicamente que dão a impressão da causalidade e da autolocomoção para o observador), o que demonstraria a primitividade de uma causalidade perceptiva, mediante a qual apreendemos fenômenos na qualidade de agentes e pacientes, de um "antes" causal e de um "depois" consequencial, culminando mesmo na percepção mais complexa de um objeto "vivo" (com os movimentos induzidos de "reptação" e "natação"; cf. Michotte, 1946, pp. 190-192). O sentido está no movimento, sendo que importa notar como todos esses predicados, inclusive os temporais, dependem dos fatores de campo, e não o inverso. Assim, não subsistem objetos ou condições físicas ou psicológicas para que, em seguida, a eles se acrescentem os fenômenos de movimento causal, de agenciamento mútuo ou mesmo de autolocomoção, já que existe uma "causalidade fenomenal" e uma "impressão original" irredutível à explicação física e à síntese intelectual (Michotte, 1946, p. 191). O que representa um avanço para a escola gestáltica, já que "o estudo desses casos permite, como será observado, descobrir a intervenção de leis proximamente aparentadas àquelas da percepção das Formas e de ligar assim a impressão causal aos fenômenos já conhecidos a este respeito" (Michotte, 1946, p. 16). A relação figural entre os objetos, tomada de maneira estática, já dependia de fatores de campo; agora é a ação ou o agenciamento entre objetos que também dependerá destas propriedades de conjunto. E é essa autonomia do campo que permite discriminar móbeis e objetos isolados, além da relação exterior e de subordinação entre um e outro. Elas já estão todas dadas no campo perceptivo, onde o objeto é apreendido como um móbil e seu horizonte como o cenário de seu movimento, em relações de reciprocidade causal e coercitiva. Num exemplo, a intimidade entre a tela do cinema e os objetos que nela se movimentam ilumina a relação entre o campo perceptivo e o corpo percipiente. O que impele a pensar o movimento como modo primitivo de doação; as coisas são movimento, e não podem ser apreendidas ou recolhidas

expressão que em princípio não funciona como teleologia dada, que funda a si mesma, que remaneja e sublima as figuras e os fundos, é preciso linguagem, espaço cultural" (Merleau-Ponty, 2011, p. 88). O que demanda uma "reforma da noção de Abschattung" onde "os dados sensoriais são já intencionais" (MerleauPonty, 2011, p. 84), porquanto possuem um valor diacrítico uns em relação aos outros, e independem de uma consciência que venha recortá-las (do centro do noema, do presente ou do cogito). É esta revisão do obstinado aparelho referencial do logos que aproximará todos os entes perceptivos e intencionais, já que não é numa presunção de referência (de um mundo como "único", de um objeto como o "mesmo") que eles podem se encontrar, mas num ambiente pré-referencial em que é justamente a "diferença" entre suas condutas perceptivas, motoras e simbólicas que os vincula. Um vínculo pela diferença, ao invés de um vínculo pela comunidade e pela referência ao mesmo. 
à parte dessa dinâmica movente a partir da qual temos a sua experiência. Ora, há uma labilidade do campo devido ao "sujeito" desta mobilidade fundamental ser já um sujeito "motor" - e o ser aqui se compreende como movimento. Todos esses fatos convidam "a buscar na situação de conjunto do campo [a] motivação do movimento e a descrever [o] sujeito de percepção de tal modo que ele seja sensível a essa situação" (Merleau-Ponty, 2013, p. 94). Cremos que a sensibilidade a este tipo de situação está na definição do sentido perceptivo, do sentido da fala e da conduta, bem como da posição e do "lugar" que o corpo ocupa no espaço, todos como écarts, como modalidades de diferenças ou desvios com relação ao campo. Mover-se e perceber são sinônimos numa relação de sentido diferencial e que, não obstante, não pode ser pensada em suas condições de possibilidade formais, mesmo naquela forma fluente da consciência do tempo, visto que a principal característica do movimento é, com o perdão do truísmo, "já estar em movimento" e deslocar-se diferenciando o campo em desvios e níveis.

O que conta para esta filosofia baseada no movimento é a capacidade de apreender ressonâncias profundas e mais ou menos transponíveis na diferenciação (no écartement) entre o sujeito e seu ambiente perceptivo, naquilo que Merleau-Ponty denomina níveau, norma ou típica, e não pensar a sua "verdade" para além dessa variação e diferenciação. Quando o campo e o esquema corporal passam a formar um sistema diacrítico é a posição da fenomenologia que junto disso se modifica. A "verdade" do movimento está na variação e não no invariante a que tal variação concederia acesso. $\mathrm{O}$ corpo pode, no máximo, mensurar a labilidade do campo em predicados sensíveis ou intelectuais, tais como aquilo que se dá 'antes', numa posição 'x', e 'depois', na posição ' $y$ '. Tais predicados são os "rastros" espaço-temporais que o corpo apreende dessa mobilidade mais fundamental e que é responsável pela diferenciação das estruturas de que fazíamos menção. Seus desvios no espaço são como que marcações do movimento; seus desvios no tempo são números que contam o movimento (numa aproximação que não parece totalmente fortuita com o livro IV da Física).

Com as modernas descobertas gestaltistas e a fenomenologia que elas reclamam, não se trata de subverter o tempo ou mesmo de contestá-lo no seu nível de descrição. Apenas de mostrar como é o movimento que engendra as capacidades cognitivas com que captamos uma duração para os entes, bem como a sua organização em um "antes" e um "depois", do mesmo modo que Michotte e outros traziam à tona uma labilidade do campo que permite à percepção compreender o agenciamento entre suas partes e, em seguida, ao pensamento distinguir entre a ordem (quem sucede quem) ou a grandeza (quem 
está ao lado de quem) dessas partes. O movimento é fundamental sem precisar ser originário, primordial sem ter que ser primeiro, visto que a "origem" e o "primeiro" são modos de contar o tempo.

Uma última consideração. No modelo da temporalidade era a passagem entre presente e passado ou porvir o "arquétipo" da relação de sentido e da relação de si a si e desenhava junto dela uma interioridade ou uma ipseidade. Este "Si" que acompanhava estruturalmente e pré-reflexivamente o escoamento do tempo não somente é tornado possível, agora, pelo movimento, como deixa de estar necessariamente previsto na lógica de sua manifestação. Michotte mostra como o movimento é capaz de gerar o sentido e a iminência de um ser que vive a si mesmo nos fenômenos de "entranhamento" e que isso não é um acidente, mas faz parte da dinâmica própria da percepção, já que para este autor não é o hábito que cria essas figuras vivas (a memória de lagartas, lesmas, peixes e pássaros é "recuperada" no movimento dos blocos), e sim o rearranjo das figuras induzido pelas experiências que enseja a "impressão visual de atividade mecânica imanente" (Michotte, 1946, p. 191). O mecanismo da percepção vê nascer a vida a partir somente do movimento, sem intermediários, nesse protoplasma que surge no lugar da caixa enquanto ela se movimenta e muda sua figura. Ali surge um "sujeito", do mesmo modo que o "meu" movimento me diferencia com relação ao campo e dá ensejo a minha perspectiva "subjetiva" com relação a ele. É, pelo menos, o viés interpretativo que Merleau-Ponty oferece a tais experimentos. E se analisamos a obra de Michotte por si mesma, parece bem ser este o problema do autor, porquanto ele anuncia que após os resultados experimentais deveria suceder uma "segunda tarefa" a fim de "compreender' o fenômeno" e de "fazer a sua teoria" ao "fornecer a prova definitiva do caráter original, primitivo, da impressão causal" (Michotte, 1946, p. 16). A fenomenologia de Merleau-Ponty é também a consecução dessa tarefa, pois estabelece o movimento como fator chave da percepção e do comportamento. As experiências de Michotte "mostram que a percepção de um movimento (de 'reptação') é solidária de uma organização da figura que faz dela um todo que tem um interior e onde se elabora um começo de 'comportamento"" (Merleau-Ponty, 2011, p. 188), e pode, ademais, ser transposta e generalizada a uma noção de sentido mais ampla, já que "algo de análogo deve existir no movimento inanimado de um "móbil"” (Merleau-Ponty, 2011, pp. 188-9). Estamos na iminência da descoberta da carne como princípio ontológico da fenomenalidade, que não liga apenas descritivamente os seres, mas estabelece um parentesco intencional entre eles e a própria descrição com que sua experiência é apreendida - a interrogação como dinâmica própria da 
carne, de sua diferenciação interna, como “órgão ontológico” (Merleau-Ponty, 1964, p. 160). ${ }^{11}$

Mas isso só é possível porque houve uma releitura da noção de gestalt como um sistema diacrítico, vale dizer, em que o valor de sua apreensão provém da diferenciação entre seus elementos. É isto o que significa dizer que a consciência ou o sentido, sob esta nova rubrica, é um écart par rapport à un niveau (Merleau-Ponty, 2011, pp. 50, 57, 79, 139), um desvio, diferença ou variação com relação a um sistema onde seus elementos só possuem valor uns com relação aos outros. O que precisa ficar claro é que a definição de sentido como desvio sobre nível é algo que só pode ser depreendido do fenômeno e da gestalt, conferindo-lhe uma autonomia em face da consciência pré-reflexiva do cogito e da intencionalidade noemática, desde que a própria fenomenalidade seja pensada de maneira diacrítica e movente. Assim, a i) noção de signo diacrítico e o ii) fenômeno do movimento preparam o campo conceitual para uma fenomenologia que não perscruta o originário.

\section{0 princípio anárquico}

Logo, parece que a crítica de Derrida não passa aqui: "a questão da possibilidade da redução transcendental não pode ficar sem resposta", diz-nos o autor e, nessa feita, identifica a questão da gênese com a possibilidade da

11 Quanto ao papel dos experimentos de Von Weizsäcker na elucidação da relação entre movimento e percepção remetemos ao artigo "L'espace et le mouvement vivant" (Barbaras, 2003, p. 170ss). Já na época deste escrito, R. Barbaras observa, contudo, um prejuízo que acompanharia toda a filosofia de Merleau-Ponty, sendo apenas renovado na formulação da ontologia de O visível e o invisível (Barbaras, 2003, p. 155). Tome-se a nota bastante comentada de Maio de 1960, onde Merleau-Ponty distingue um sentido para a "minha carne", que sente a si mesma, e outro para a "carne do mundo", que é apenas sensivel e "não senciente" (MerleauPonty, 1964, p. 304). Fazemos menção à esta passagem controversa e tida por Barbaras como o exemplo mais claro da dificuldade que Merleau-Ponty tem para elucidar ao mesmo tempo a unidade e a diferença entre corpo e mundo, porque é justamente na sequência desta nota que Merleau-Ponty invoca Michotte: "a carne do mundo não é se sentir como minha carne - Ela é sensível e não senciente - Ainda assim eu a denomino carne (por exemplo o relevo, a profundidade, a "vida" nas experiências de Michotte) para dizer que ela é pregnância de possíveis [...]", o que nos parece indicar que a pretensa distinção ontológica na verdade poderia ser lida segundo a experiência do movimento e do princípio de diferenciação que agora sabemos nela estar contido. Além disso, ela não faz referência apenas aos movimentos específicos de auto-locomoção (natação e reptação; a "vida"), mas a todo tipo de movimento percebido, e isso conforme a sua leitura de Michotte. Obviamente esta nota invoca um problema fundamental em fenomenologia - a relação entre a subjetividade $e$ o mundo -, mas a aposta em Michotte e na concepção de sentido como movimento que dele deriva fornece a inteligibilidade necessária ao texto. Cremos que é a passagem da diferenciação ao movimento, e do movimento como diferenciação, doravante compreendida pura e simplesmente como "carne", que recoloca o problema da correlação intencional numa nova chave, para não dizer que se trata talvez mesmo de superá-lo, em prol de um momento anterior e, ainda assim, dotado de experiência e de sentido. Como Merleau-Ponty já havia sugerido em 1959 "a teoria moderna da percepção é uma fenomenologia (Michotte) e desvela o ser bruto, o mundo 'vertical"' (1964, p. 254), e, em seguida, que "a análise saussureana [...] das significações (como diferenças de significações), confirma e reencontra a ideia da percepção como desvio com relação a um nivel" (1964, p. 255). 
fenomenologia, como "a questão da possibilidade da questão, a abertura mesma [...]" (Derrida, 1967, p. 251). Mas, caso a fenomenologia não seja mais animada pela Ruckfräge husserliana, pela questão retrospectiva e que sempre retorna acerca do que há de originário nos fenômenos, desta "abertura" (Vorhaben), talvez o problema todo tenha que ser deslocado e, junto dele, a sua crítica. Quando Derrida escreve que "a presença à consciência fenomenológica do Telos ou Vorhaben, antecipação teorética infinita que se dá simultaneamente como tarefa prática infinita, é indicada a cada vez que Husserl fala da Ideia no sentido kantiano" ele tem razão em aproximar a fenomenologia desta obsessão pela referencialidade, pelo invariante e pelo universal. Mas, por outro lado, quando completa que "talvez pareceria que esta Ideia é a Ideia ou o projeto mesmo da fenomenologia, o que a torna possível superando seu sistema de evidências ou de determinações atuais, superando-o como sua base ou seu fim" (Derrida, 1967, p. 250) ele identifica a fenomenologia à presunção do universal como ideia no sentido kantiano. Ademais, identifica a fenomenologia à ocupação com esta ideia que liga todas as aparências no infinito. Obviamente, esta não parece ser a única alternativa e tudo depende da compreensão que se tem da fenomenalidade e de seu logos. Noutras palavras: depende do modo como se concebe $o$ fenômeno, sendo que este "como" da fenomenalidade afeta "o quê" por meio dela se fenomenaliza. O esforço deste trabalho está em mapear a partir de Merleau-Ponty uma descrição que não possui como tema o originário, nem a garantia, seja na base, seja no fim, de uma arqueologia ou teleologia do sentido como "único" e o "mesmo". A passagem entre os anos 1940 e 1950 evidencia bem este pré-juízo da referencialidade e como ela deixa de ser parte necessariamente integrante da intencionalidade. Trata-se, antes, da tendência que um fenômeno-pivô ou fenômeno-desvio possui para se diferenciar de outro e se alastrar como fenômeno-fundo ou fenômeno-nível. Em suma, se a lógica da manifestação ocorre de um outro modo, como procuramos mostrar através da compreensão do "movimento" e da "diferenciação", é também o sentido daquilo que é ali manifesto que se modifica.

A questão da origem era crucial porque havia uma pressuposição da fenomenalidade como algo primeiro, dado em presença, e isso levava a considerar a temporalidade como constitutiva da subjetividade. Mas não é preciso fazer como Derrida e, junto do originário, romper com toda fenomenologia. Antes que ruptura, em direção de um outro completamente Outro, irredutível a qualquer experiência, trata-se de uma reforma, na qual é a própria ideia de "fundamento" que se encontra relativizada, mas sem que com isso percamos a tenacidade da experiência. Lembremo-nos da formulação para o problema da imanência e da transcendência, tal como pensada por Merleau- 
Ponty ainda em 1945, e que mencionamos no início (Merleau-Ponty, 1945, p. 376). Havia nela uma exigência aparentemente disparatada: a de que um sujeito situado por seu corpo e por seu olhar no mundo ("sem abandonar seu lugar e seu ponto de vista") pudesse se abrir àquilo que não lhe está dado ("a um Outro absoluto que ele prepara no mais profundo de si mesmo"). Uma passagem semelhante está no "anexo" de $O$ Visível e o Invisível, que termina inesperadamente a sua obra; contudo, a sutil mudança de sua formulação revela uma outra abordagem para o problema

Nós interrogamos nossa experiência, precisamente para saber como ela nos abre àquilo que não é nós. E não está sequer excluído a partir daí que encontremos nela um movimento em direção disto que não poderia em nenhum caso nos estar presente no original e de que a ausência irremediável contaria, assim, dentre nossas experiências originárias. (Merleau-Ponty, 1964, p. 209)

Que fundamento dar a esta falta de fundamento? Não nos enganemos, aqui não é o sujeito que prepara o mundo, nem o mundo que prepara a sua percepção. Nada há de original na sua fronteira, mas é a diferença entre eles que pode dar a medida daquilo que insistimos em chamar de "originário" e que, doravante, deixa de ser original. É esta fenomenologia sem origem que importa delimitar e caracterizar devidamente. Pois é somente aqui que podemos notar uma ruptura com o "princípio dos princípios" husserliano em prol de um novo princípio que obtura sua intuitividade e restabelece a experiência um momento antes, naquilo que "não poderia em nenhum caso nos estar presente no original", visto que não se doa como presença, mas sim como diferença e no desvio que o movimento lhe impõe. Neste outro nível é possível interrogar o fundamento desta fenomenologia. E, por incrível que pareça, quando a diferença (com o movimento e a dinâmica diacrítica do sensível) passa a ser fundamento, em certo sentido, essa análise deixa de ter fundamento (deixa mesmo de necessitar dele). A descrição genética torna-se interrogação filosófica da "passagem" e o filósofo passa a ser aquele que interroga não o universal, nem sua impossibilidade pelo relativo, mas a diferença; aquele "para quem há o reconhecimento das particularidades que unem" (Merleau-Ponty, 2003, p. 108). É essa diferença que vincula, mas ela não pode estar na pretensa camada comum do originário, e sim no nível do acontecimento - daquilo que "nos abre àquilo que não somos."

Trata-se, então, de uma fenomenologia que descreve a passagem entre algo que é individuado, singularizado e sua normatização ou nivelização (justamente o que Merleau-Ponty chamava de "instituição", seja na vida de um indivíduo ou de uma sociedade). Não há consciência originária, protoconsciência, 
Urbewusstsein, na medida em que o ser não se doa enquanto presença a uma intuição. O dado não está no centro do campo fenomenal, como no presente do tempo ou no núcleo do noema; não há um centro. Mas, retirado o originário da fenomenalidade, sem a categoria do primeiro, de que afinal falamos? De um contato, de um acontecimento, em que algo pode figurar como "mundo", mas a partir do qual um "outro mundo" também é permitido. A possibilidade da fenomenologia estaria justamente nisso: que, sem deixar de ser a filosofia, sem tornar-se uma descrição regional, ela tenha que permanecer, num sentido certamente controverso, uma fenomenologia anárquica. Não sendo então uma falta, um limite ou um contrassenso, é nesta impossibilidade que reside a sua possibilidade.

\section{Referências}

BARBARAS, R. "De l'être du phénomène. Sur l'ontologie de Merleau-Ponty". Grenoble: Millon, 1991.

. "Vie et intentionnalité: recherches phénoménologiques". Paris: Vrin, 2003.

COLONNA, F. "Merleau-Ponty et le renouvellement de la métaphysique". Paris: Ed. Hermann, 2014.

DERRIDA, J. "Le problème de la genèse dans la philosophie de Husserl”. Paris: Presses Universitaires de France, 1990.

. "Le Voix et le Phénomène: Introduction au problème du signe dans le phénoménologie de Husserl”. Presses Universitaires de France, 1967. . "L'Archeologie du frivole: Lire Condillac". Paris: Denoël/Gontheier, 1973.

FERRAZ, M. S. “Fenomenologia e ontologia em Merleau-Ponty”. São Paulo: Papirus, 2009.

HUSSERL, E. "Zur Phänomenologie des inneren Zeitbewusstesens (1893-1917)". Husserliana Band, Vol. X. R. Boehm (ed.) Hague: Martinus Nijhoff, 1968.

. "Lições para uma fenomenologia da consciência interna do tempo". Trad.

Pedro M. S. Alves. Lisboa: Imprensa Nacional/Casa da Moeda, 1984.

. "Ideias para uma fenomenologia pura e para uma filosofia fenomenológica". Trad. Márcio Suzuki, Aparecida: Ideias \& Letras. 2006.

. "Méditations cartésiennes". Trad. G. Peiffer et E. Lévinas. Paris: Vrin, 1953.

"Expérience et jugement". Trad. D. Souche. Paris: PUF, 1970.

MACKSEY, R., DONATO, E. "The Structuralist Controversy: The languages of criticism and the sciences of man”. Baltimore and London: The John Hopkins Press, 1970.

MICHOTTE, A. "La perception de la causalité". Paris: Vrin, 1946.

MERLEAU-PONTY, M. "La Structure du Comportement”. Paris: PUF, 1967.

. "L'Institution-La Passivité”. Berlin, 2003. 
."Le monde sensible et le monde de l'expression". Genebra: MetisPresses, 2011. . "Le Visible et le Invisible”. Paris: Gallimard, 1964.

. "Phénoménologie de la Perception", Paris: Gallimard, 1945.

. "Sens et non Sens". Paris: Gallimard, 1997.

. "Signes". Paris: Gallimard, 1968.

. "Merleau-Ponty à la Sorbonne". Grenoble; Cynara, 1988.

MOURA, C. A. R. "Racionalidade e crise: Estudos de história da filosofia moderna e contemporânea”. São Paulo: Discurso Editorial, Edufpr, 2001.

. "Intencionalidade e existência em Merleau-Ponty". In: Merleau-Ponty em

Salvador. Salvador: Arcadia, 2008.

MOUTINHO, L. D. S. "Tempo e sujeito: o transcendental e o empírico na fenomenologia de Merleau-Ponty”. Revista Dois Pontos, Vol. 1, Nr. 1, 2004.

PEILLON, V. "La tradition de l'esprit: itinéraire de Maurice Merleau-Ponty". Paris:

Grasset, 1994. 
